\title{
MYOCARDIAL AND HEPATIC NECROSIS AND BONE MARROW SUPPRESSION IN MICE INDUCED BY SINGLE ADMINISTRATION OF CHAETOCHROMIN*, A POLYPHENOLIC MYCOTOXIN PRODUCED BY CHAETOMIUM spp
}

\author{
Kohichiro Ohtsubo \\ Department of Clinical Pathology. Tokyo Metropolitan Institute of Gerontology
}

\begin{abstract}
A sublethal dose of $140 \mathrm{mg} / \mathrm{kg}$ b.w. of chactochromin, a mycotoxin produced by Chaetomium spp. caused lesions in various organs characterized by rather slow-developing necrosis and repair in the ICR male mice. With 3 to 4 days of latent period, focal necrosis of the liver and myocardium and diffuse hematopoietic cell necrosis of the bone marrow were observed histologically. Necrosis also occurred in the spleen. lymph nodes, and thymus but intestinal epithelial cells were not affected. Electron microscopic examination of the heart revealed mitochondrial swelling and degeneration showing myelin-like figures at 3 days, focal and single $\propto$ ll necrosis with disruption of myofibrils at 7 or 8 days. After 11 days calcification developed in necrotic foci of the heart and liver, ensuing foreign body reaction up to 24 days. The bone marrow recovered with no sequelae by 14 to 24 days. (J Toxicol Pathol 2: 163 174, 1989)
\end{abstract}

Key wonds: Chaetochromins, Oral toxicity, Electron microscopy, Mouse. Cardiac injury

\section{Introduction}

Most of the fungal species belonging to genus Chaetomium produce various mycotoxins including caetoglobosins, a series of compounds having unique cytochalasan structure ${ }^{3}$. Furthermore, chaetochromin was isolated from the culture of $C$. thielavioideum ${ }^{4}\left(=C\right.$. virescens $\left.s^{5}\right)$, and identified as $2,2^{\prime}, 3,3^{\prime}$-tetrahydro-5, $5^{\prime}, 6,6^{\prime}, 8,8^{\prime}$-hexahydroxy-2, 2', 3, 3'-tetramethyl- $[9,9-b i-4 H$-naphtho [2, 3-b] pyran-4, 4' -dione $]^{\circ}$ (Fig. 1). Among the fungal strains tested, a strain of $C$. gracile, 73-S$T-Y-3$, was found to be the best producer of

\section{大坪浩一郎}

Accepted for publication: September I, 1989

Mailing address: Kohichiro Ohtsubo, Department of Clinical Pathology, Tokyo Metropolitan Institute of Gerontology, 35-2, Sakaecho. Itabashiku. Tokyo 173. Tokyo.

- Rocently, many derivatives of chaetochromin have been identified and now chaetochromin is renamed as chaetochromin $A(1,2)$, but in this report it is referred as previously. chaetochromin on rice culture ${ }^{6}$. Fungi of Chaetomium spp. often produce many mycotoxins simultaneously. For example. C. thielavioideum yields sterigmatocystins $s^{5}$, chaetocin and eugenitin in addition to chaetochromint. By far, no naturally occurring contaminations of food- and/or feedstuffs by chaetochromin have been reported.

A screening test using HeLa cells in culture revealed its potent cytotoxic property4. A pre-

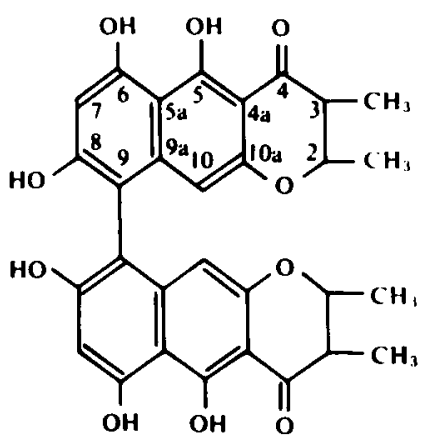

Fig. 1. Chemical structure of chaetochromin (= chaetochromin A) (Courtesy of Prof. S. Natori). 
Table 1. Deaths of the Mice Receiving a Single Administration of Chaetochromin

\begin{tabular}{|c|c|c|c|c|c|c|c|c|c|c|c|c|c|}
\hline \multirow{2}{*}{$\begin{array}{c}\text { Dose } \\
(\mathbf{m g} \mathbf{~ k g})\end{array}$} & \multicolumn{12}{|c|}{ Life Time (Days) } & \multirow{2}{*}{$\begin{array}{l}\text { Death } \\
\text { Rate }\end{array}$} \\
\hline & $<4$ & 5 & 6 & 7 & 8 & 9 & 10 & 11 & 12 & 13 & 14 & 17 & \\
\hline 100 & 0 & 0 & $\mathbf{0}$ & 0 & 0 & 0 & $\mathbf{0}$ & 0 & 0 & 0 & 1 & 1 & $2 / 6$ \\
\hline 140 & $\mathbf{0}$ & $\mathbf{0}$ & $\mathbf{0}$ & 2 & 0 & 1 & 2 & 2 & 4 & 1 & 1 & 0 & $13 / 20$ \\
\hline 200 & $\mathbf{0}$ & $\mathbf{0}$ & 2 & 0 & 0 & $\mathbf{0}$ & 1 & 0 & 1 & 0 & 0 & 0 & $4 / 6$ \\
\hline 400 & 1 & 1 & $\mathbf{0}$ & 0 & 0 & $\mathbf{0}$ & 2 & 2 & 1 & & & & $6 / 6$ \\
\hline
\end{tabular}

liminary test of the toxin to mice revealed high mortality by ip. injection of $10 \mathrm{mg} / \mathrm{kg}$ b.w., with hepatic and lymphoid tissue damage? . Considering the route of natural exposure. however, oral administration of the pure substance and feeding of the moldy diet ${ }^{\text {an }}$ were our main concern. The purpose of this study is to demonstrate the oral toxicity of this compound, especially to describe the various pathological changes in the bone marrow, liver. and heart of mice.

\section{Materials and Methods}

Male mice of ICR strain purchased from Shizuoka Agricultural Cooperation for Laboratory Animals (Hamamatsu, Japan) were used. Five mice were caged together in an aluminum cage with sawdust bedding. Feed (CRF-1, Oriental Yeast, Co. Lid., Tokyo) and water ( $\mathrm{HCl}-$ acidified, pH 3, to prevent growth of Pyocyaneus) were given freely. The room temperature and humidity were maintained at 23 to $25^{\circ} \mathrm{C}$ and 50 to 60\%, respectively.

Chaetochromin was isolated and provided by Drs S. Natori, Meiji Pharmaceutical College, and

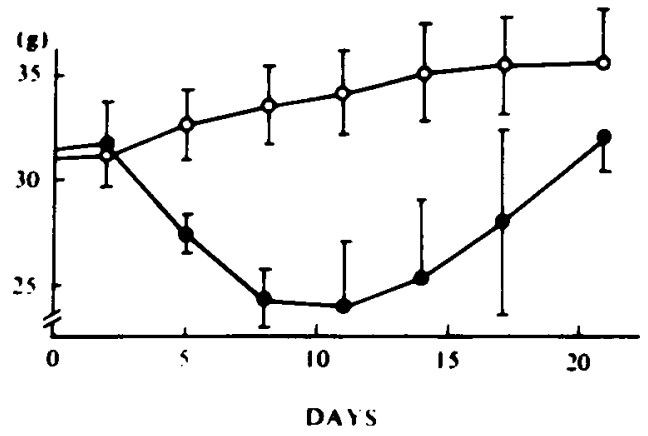

Fig. 2. Body weight changes (mean \pm S.D.) of mice administered $140 \mathrm{mg}$ kg b.w. chactochromin (๑) and control animals ( $\supset$ ). Marked body weight loss with slow recovery after single administration of the toxin was apparent.
S. Sekita, National Institute of Hygienic Sciences, Tokyo. It was dissolved in DMSO (spectrograde, Merck) and an amount of $0.1 \mathrm{ml} / 20 \mathrm{~g} \mathrm{b.w}$. was given by gastric gavage. Full autopsy and routine histological examination were performed on all succumbed or sacrificed animals.

For electron microscopical examination, the heart was removed and cut in 1-2 mm slices from apex to base, parallel to the atrioventricular groove. Free wall of the left ventricle from a slice near the middle portion was cut in 1-2 mm cubes and fixed overnight in $2 \%$ glutaraldehyde in $0.1 \mathrm{M}$ cacodilate buffer, post fixed for $2 \mathrm{hr}$ in buffered $1 \%$ osmium tetroxide, dehydrated in graded alcohols and embedded in Epon 812. Ultrathin sections were cut on a Reichert's Ultrotome 3, doublestained with uranyl acetate and lead citrate and examined with Hitachi H-600 electron microscope.

\section{Results}

\section{Lethal Toxicity}

Mortality and survival days of the mice receiving 100 to $400 \mathrm{mg} / \mathrm{kg}$ b.w. chaetochromin are shown in Table 1. Survival time was widely dispersed but the death occurred most frequently in the second week. LD 50 was estimated as 152 $\mathrm{mg} / \mathrm{kg}$ body weight (Behrens' method). In the course of the disease, even the mice given the highest dose were first seen ill on the 3rd day, when weak activity, loss of glossiness of the hair with ruffling, and anorexia developed. The body weight fell rapidly thereafter, and from the end of the second week, the survived mice gradually recovered as the symptoms subsided. Jaundice was symptomatically unrecognized.

Time Course Study

To observe the development of lesions, 42 mice received a sublethal dose of $140 \mathrm{mg} / \mathrm{kg}$ b.w. of chaetochromin in 3 separate experiments. 


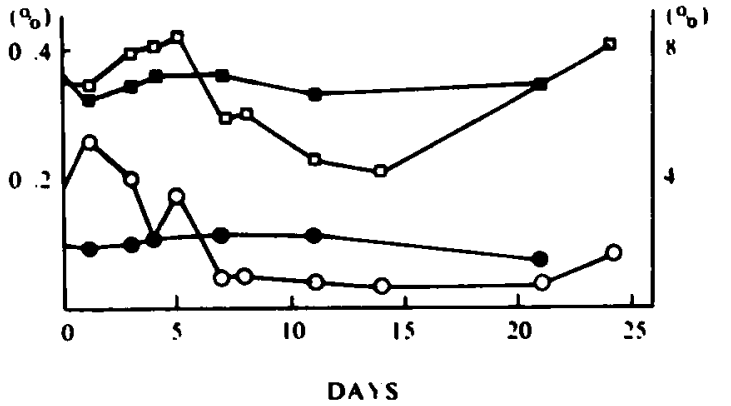

Fig. 3. Changes in the relative weights ( $\%$ of body weights) of the liver $(-)$ and kidneys $(\bullet)$ to the right scale and of the spleen ( $D$ ) and thymus (o) to the left scale. Means of 3 to 4 mice sacrificed at each point are shown.

Groups of 3 or 4 mice were killed at 1, 3, 4, 7, 8, 11 . 14, 21, and 24 days. The mean body weight of the surviving animals is shown in Fig. 2. The decrease of the relative weight of the thymus and spleen was remarkable, while those of the liver and kidneys did not change significantly (Fig. 3 ). The spleen was smallest at days 11 to 14, and enlarged at days 21 to 24 . The severity of the lesions in each organ is summarized in Table 2. The animals showed rather great variance in terms of organ involvement as well as severity of the lesions.

At day 1 no lesion was found except for glycogen depletion from the centrilobular area of the liver (3/7). At 3 to 4 days, fine vacuolation of myocardial cells was seen $(2 / 10)$. In the spleen, follicular cells were pyknotic, and $\mathrm{T}$-cell zone lymphocytes were depleted $(6 / 10)$. Correspondingly, the thymus showed cortical lymphocyte depletion $(3 / 10)$. Glycogen depletion from the liver cells was more extensive (8/10). Focal and/ or bridging necrosis of the intermediate zone (Fig.
4) was noticeable in 3 mice with variable cellular features of coagulative change, ballooning, and pyknosis. The bone marrow was unremarkable.

Characteristic changes were apparent at 5 to 8 days. In the heart, there was diffuse vacuolation of the myocardial cells (7/11). In 2 mice, patchy coagulation necrosis of the myocardium was found (Fig. 5) with early calcium deposition. The hepatic lesions were more extensive and severer than previously. Submassive, bridging and focal necrosis of coagulative and ballooning nature with inflammatory reaction was mainly located at the intermediate and centrilobular zone. Glycogen depletion and fine, droplet fatty change were found in the liver cells of perinecrotic areas. In the bone marrow, scarce nucleated cells were remaining with focal hemorrhages, although reticulum tissue framework was well preserved. In the spleen, lymphocytes depletion was extreme, almost all hematopoietic cells disappeared from the red pulp as well as in the bone marrow. The thymus and lymph nodes showed cortical atrophy with necrotic cells.

At 11 to 14 days, vacuolar change of the heart was extensive (6/6), with calcified foci in 2 . The spleen $(6 / 6)$, thymus $(3 / 3)$, lymph nodes $(2 / 2)$, and bone marrow (6/6) (Fig. 7) were almost totally acellular but tiny regenerative foci were found. The liver showed regenerative activity (Fig. 6) : areas of larger necrosis were well demarcated, showing calcification or resorption, with mitotic figures of the neighboring hepatocytes ( 3 / 6). In the remaining 3 , necrosis was no more seen, although mitotic figures suggested the preceding hepatocyte damage.

At 21 and 24 days, the left ventricle of the heart was markedly dilated (Fig. 8). Calcified

Table 2 Histological Changes of the Organs of Mice Administered Orally $140 \mathrm{mg} / \mathrm{kg}$ of Chactochromin

\begin{tabular}{lcccccccccc}
\hline \multicolumn{1}{c}{ Days } & 1 & 3 & 4 & 5 & 7 & 8 & 11 & 14 & 21 & 24 \\
\hline Heart & - & $-1+$ & + & + & + & + & $\#$ & + & + & + \\
Liver & - & + & + & + & + & + & + & + & + & - \\
Bone Marrow & - & - & + & + & + & + & + & + & + & + \\
Spleen & - & - & + & + & + & + & + & + & + & - \\
Thymus & - & - & + & + & + & + & + & + & + & \\
\hline
\end{tabular}

Severity of the lesions are expressed semi-quantitatively with - (no lesions) through * (peak of lesion). 


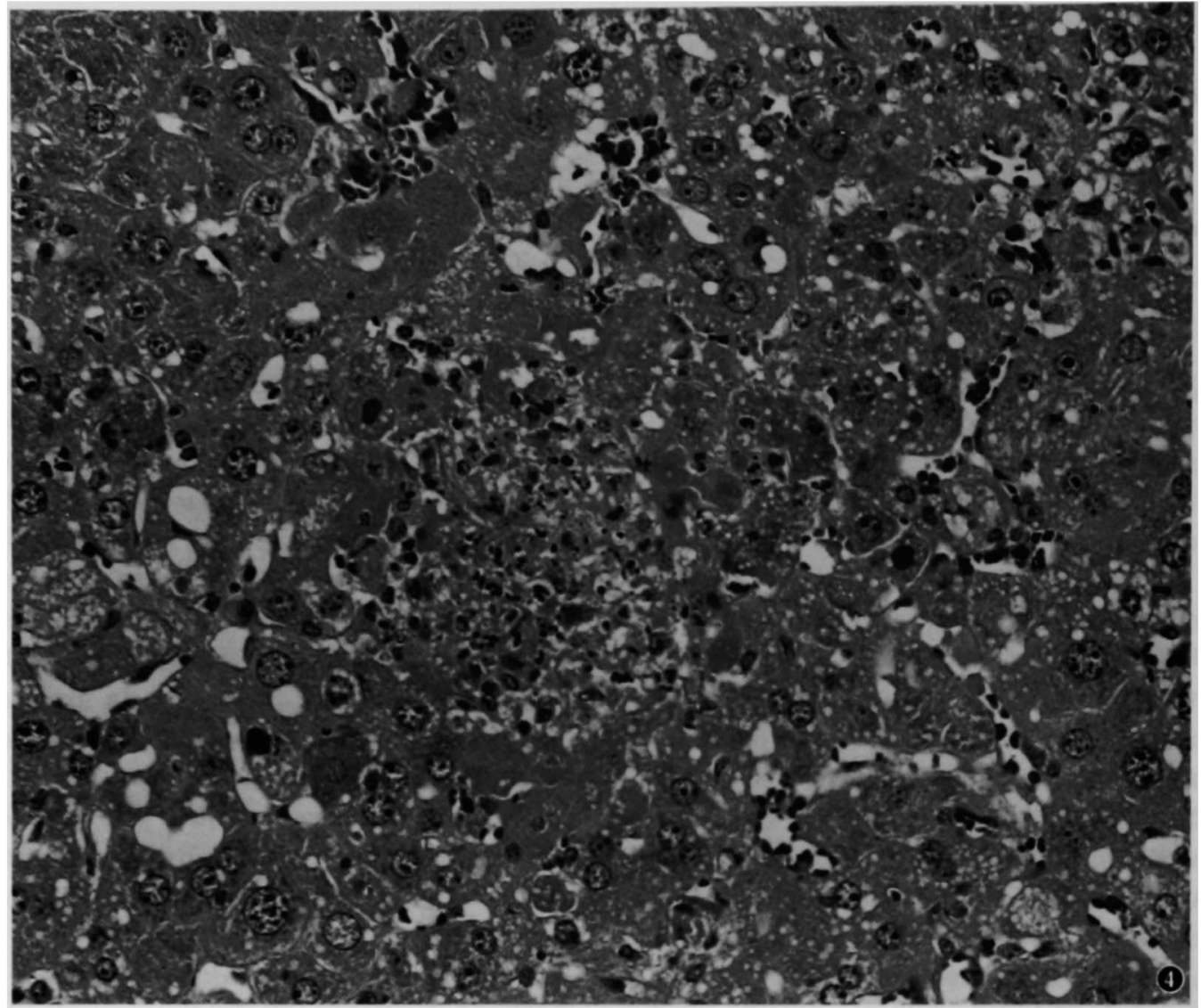

Fig. 4. Focal necrosis in the intermediate zone of the liver lobules at 7 days after toxin administration. Vacuolated cells are seen in the centrilobular zone. No noticeable changes in the periportal zone. H.E. $\cdot 320$.

foreign body granulomas were diffusely scattered in the myocardium (6/8) (Figs. 8 and 9), but no vacuolation was found. The spleen was hyperplastic, the thymic cortex was still hypocellular. and the bone marrow was hypocellular with fatty change. The liver was unremarkable except for scattered foci of macrophages (3/8).

\section{Electron Microscopy of the Heart}

Myocardial tissue from 2 to 4 animals sacrificed at $1,3,4,7$, and 11 days were subjected to electron microscopic study.

At day I when no definite change was found by light microscopy, electron microscopical examination revealed the earliest change; small myelinlike structures in the mitochondria located beneath the cytoplasmic membrane. Some mitochondria were swollen with blurred cristae. Myofibrils were unremarkable. Occasionally endothelial cells of the capillaries were swollen and pericapil- lary edema was noted. At 3 or 4 days, mitochondrial swelling was marked and myelin-like structures were numerous and diffusely distributed in the cytoplasm. Myofibrils were occasionally loose, but no necrosis had occurred. Interstitial edema was marked with cellular debris.

At 7 to 11 days (Figs. 10 and 11 ), mitochondrial alteration was extensive, with ballooning, loss of cristae, and myelin-like figures. Occasionally myofibrils were dissociated and necrosis was found (Fig. 12). Mineralization of mitochondria was suggestive by electrondense deposits (Fig. 12). After 11 days, calcification of myocardial cells was apparent in toluidine-blue stained semithin sections as well as histological sections.

\section{Discussion}

Because of limited attention to the organs in which toxic injury is most prominent, organs with 

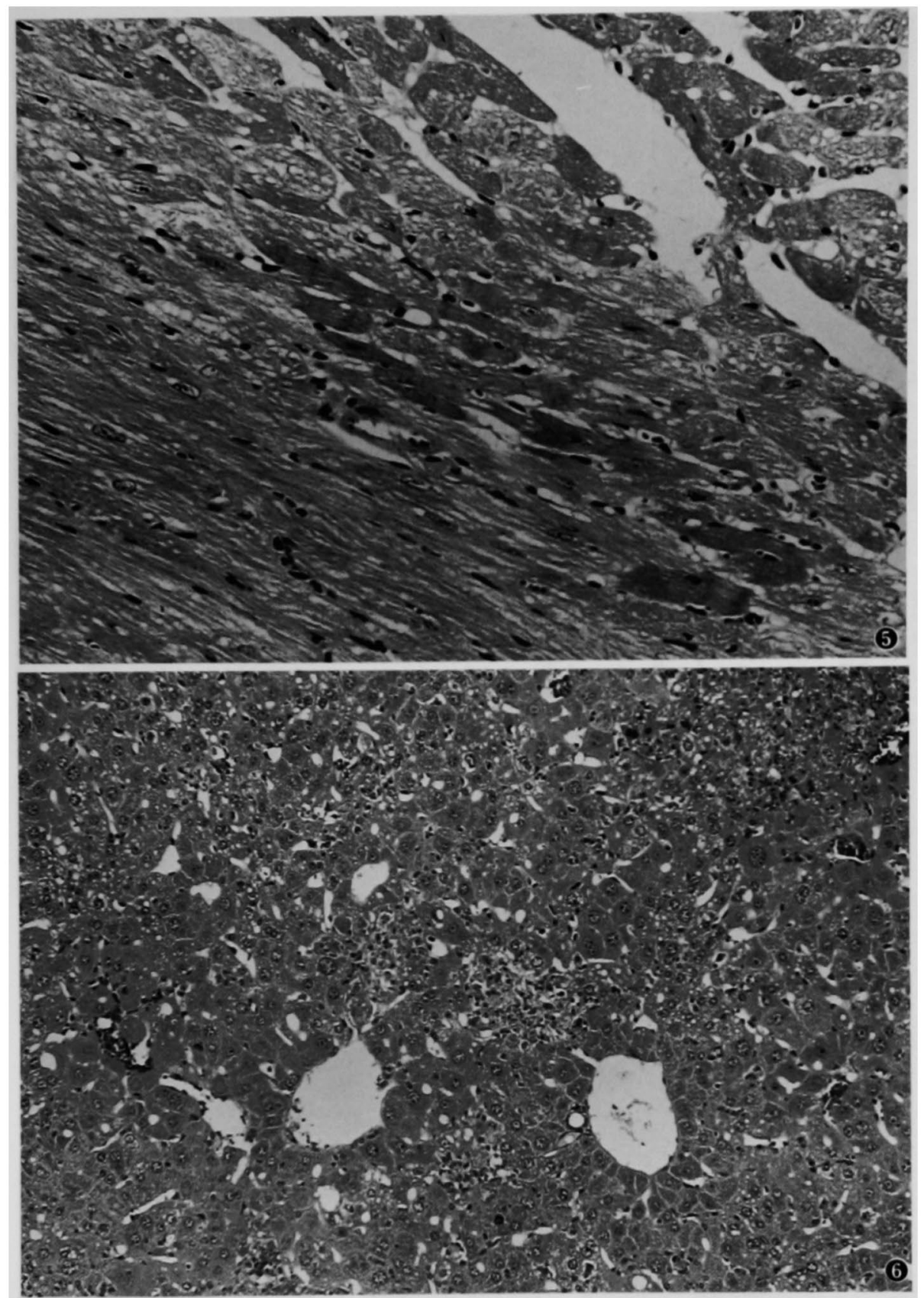

Fig. 5. Patchy coagulation necrosis and diffuse vacuolation, corresponding to myelin-like figures in electron micrographs, of the myocardium. H.E., $\times 270$.

Fig. 6. Patchy intralobular necrosis, in recovery, of the liver at 11 days after toxin administration. H.E, $\times 130$. 


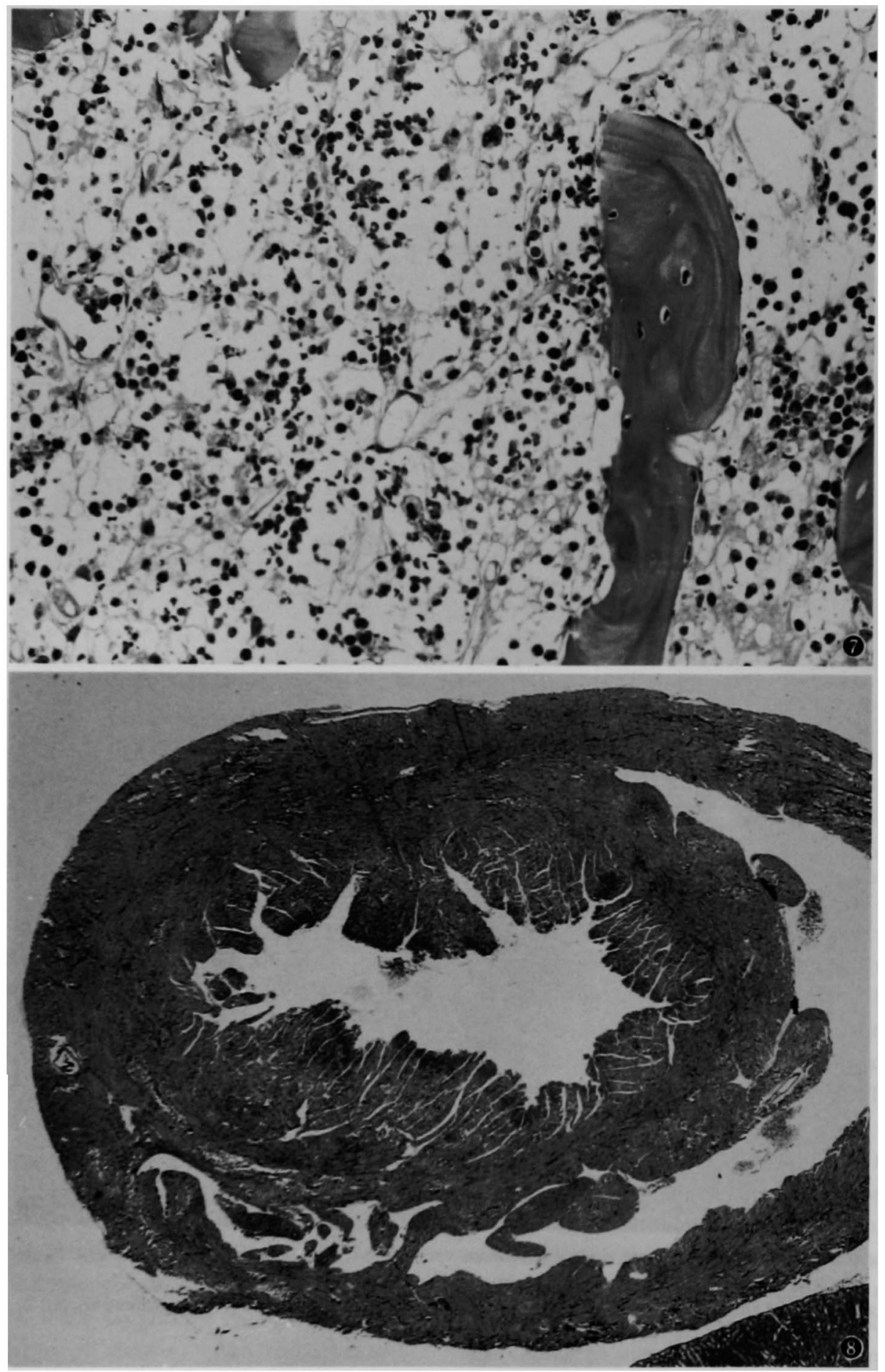

Fig. 7. Extensive bone marrow damage. A few hematopoietic cells remain in small clusters. H.E., $\times 320$.

Fig. 8. Low power view of the left ventricle of the heart showing dilatation and scattered, calcified foreign body granulomas. 21 days. H.E., $\times 23$. 


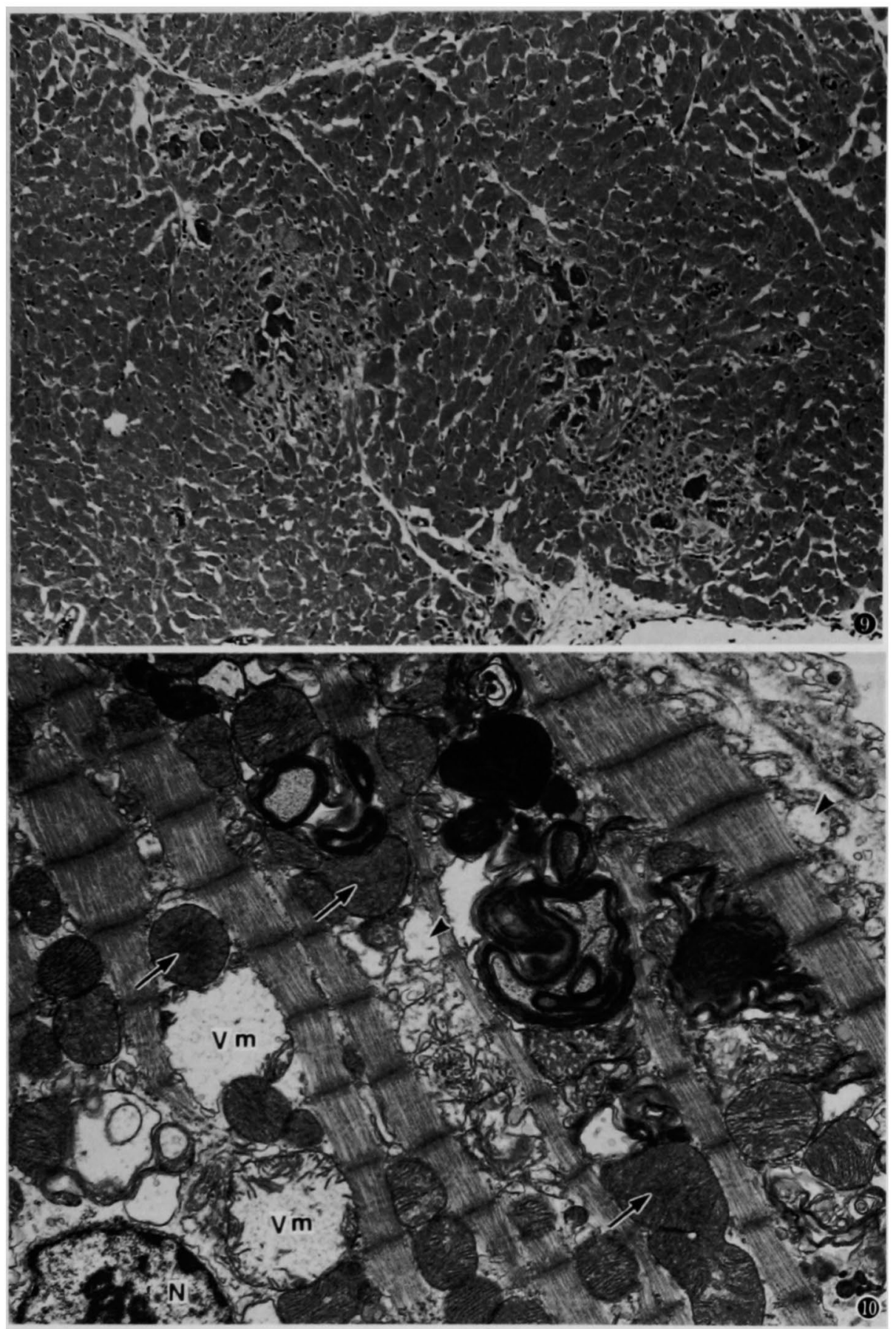

Fig. 9. Higher magnification of foreign body type granulomas in the myocardium following necrosis and calcification. The granulomas are being absorbed at 24 days after toxin administration. H.E., $\times 135$.

Fig. 10. Early myocardial cell changes with myelin-like figures, mitochondria with condensation of cristae (arrows), and vacuolation ( $\mathrm{Vm}$ ). Frequently $\mathrm{t}$-systems were dilated (arrowheads). $\times 9,400$. 

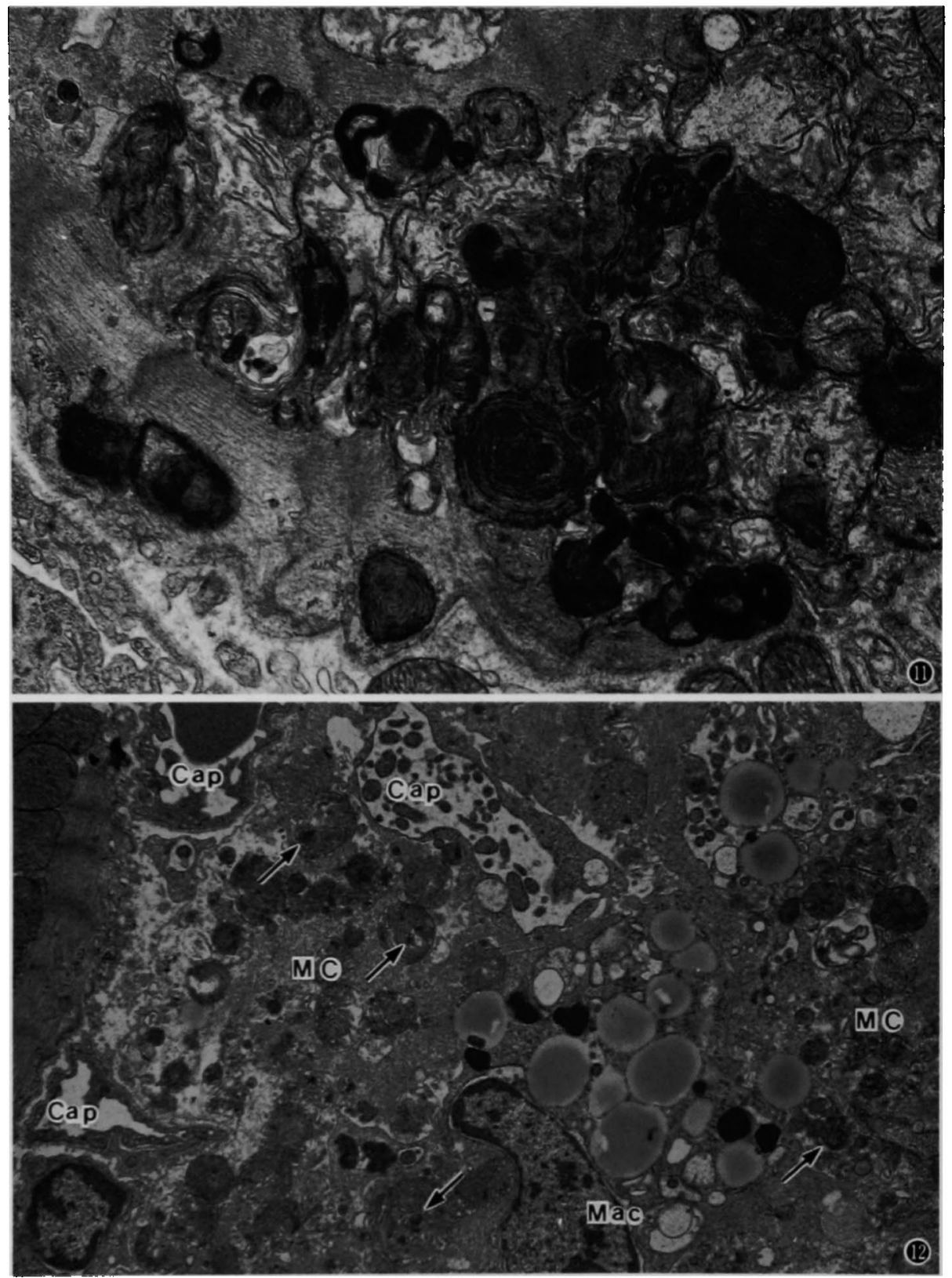

Fig. 11. Accumulation of myelin-like figures in a more advanced lesion. Myofibrils are degenerated and striations blurred. Mitochondrial swelling is also noted. This type of degeneration occurred diffusely and mostly subsided by 24 days. $\times 14,000$.

Fig. 12. Focal necrosis in the myocardium. Two necrotic myocytes (MC) and a macrophage (Mac) between them. Severe lytic change of myofibrils, condensation of mitochondria with fine mineralization (arrows), increased lysosomes and lipid droplets. The macrophage is in active phagocytosis of myocyre debris. Note a relatively well preserved myocardial cell adjacent to the damaged cell on the left edge. Capillaries (Cap) and interstitium are unremarkable. Sacrificed at 7 days. $\times 7,200$. 
subtle lesions have often been neglected. Thus, histological examination of the heart has been rarely performed in acute toxicity tests when the gross appearance was unremarkable. After adriamycin cardiotoxicity was recognized, it has been more widely known that drug- or toxininduced cardiac injury is not rare. In this connection, more than $\mathbf{2 0 0}$ reports on cardiotoxicity have been listed in the Current Contents in the last 2 years.

Chaetochromin is an example of such cases. In the first preliminary experiment, we noticed severe body weight loss with relatively unremarkable gross findings. So we performed complete histological examination of the mice and found multiple organ lesions including the liver, bone marrow, and lymphoid organs'. Fortunately, a strain of $\boldsymbol{C}$. gracile yielded about $3 \mathrm{mg} / \mathrm{g}$ chaetochromin on rice culture, and we were able to perform a feeding trial of the moldy rices and the present experiment.
By feeding moldy rice containing $30 \mathrm{ppm}$ chaetochromin for 14 weeks with interim kills, hepatic and hematopoietic injuries were apparent after 2 weeks". Cardiac lesions were not observed in the mice of these feeding experiments. A quite high, sublethal dose of chaetochromin was required to cause cardiac lesions by single oral administration. The lesions developed slowly with its peak at 7 to 10 days. Myocardial changes were characterized by mitochondrial alterations, diffuse vacuolation with profuse myelin-like structures, and focal necrosis followed by calcification and foreign body reaction. The ventricles are dilated representing heart failure in the $3 \mathrm{rd}$ and 4 th weeks.

It the feeding experiment ${ }^{\text {a }}$, the liver lesions consisted of single cell or centrilobular necrosis, followed by macrophage reaction. Peripheral portion and Glisson's triangles of the liver were unremarkable. The lesion was essentially similar to the present experiment. In the bone marrow,

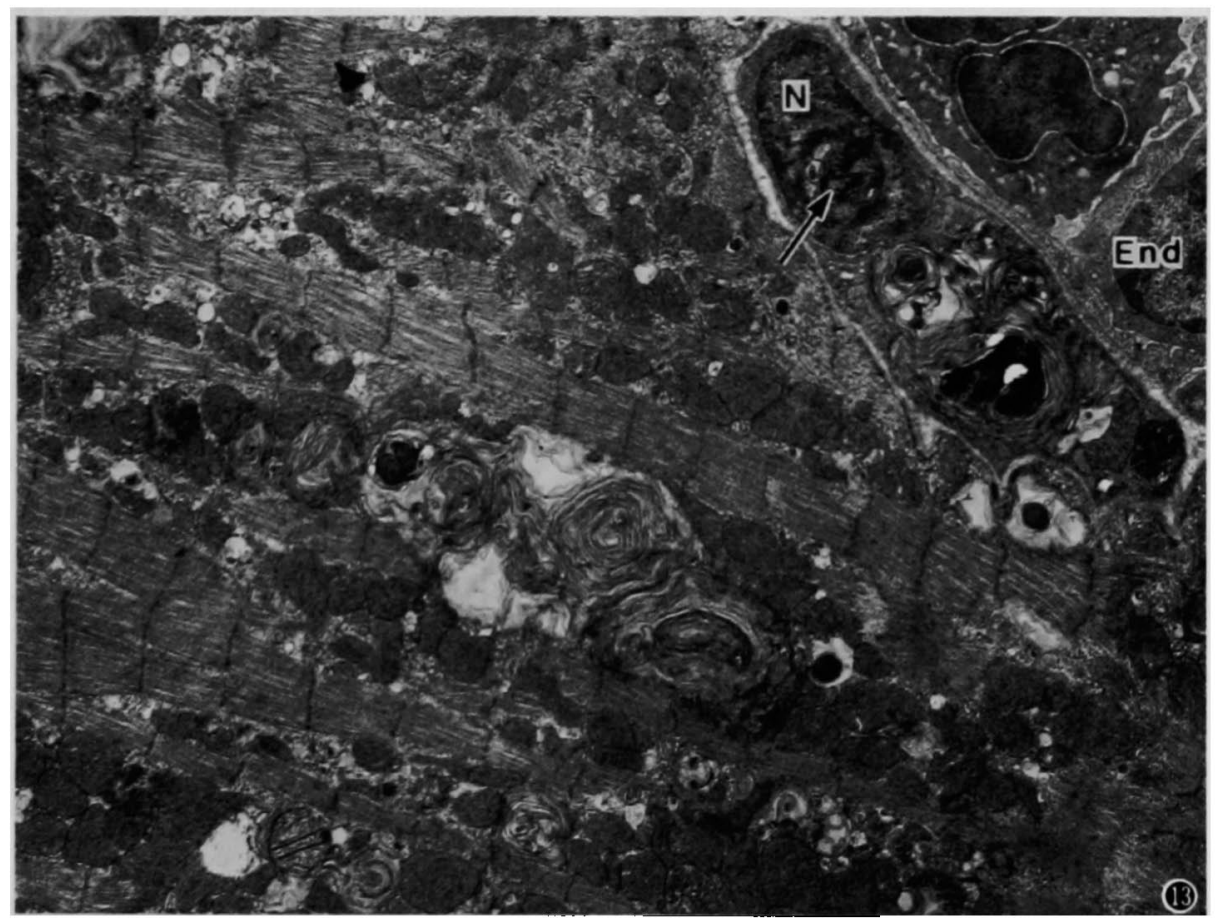

Fig. 13. Cardiac lesion induced by xanthoascin. The mice was sacrificed 4 weeks after single subcutaneous injection of the toxin $(20 \mathrm{mg} / \mathrm{kg}$ b.w.). Myelin-like figures similar to those induced by chaetochromin, are accumulated among the atrophic degenerative myofibrils. Moreover, similar membranous whorls (arrow) are present in the cytoplasm and nucleus $(\mathrm{N})$ of a fibroblast (upper right). The intranuclear membranous structures were also seen in the bronchial and alveolar epithelia and glomerular epithelial cells ${ }^{10}$. End : endothelial cell. $\times 6,200$. 
almost all hematopoietic cells disappeared, showing aplastic marrow as in the present experiment. Hematopoiesis in the spleen was temporarily suppressed until 6 weeks, then gradually recovered, with increase of the weight. The splenic change was compatible with the results of the present experiment of 24 days. The lymph nodes and thymus were markedly atrophic as well as in the present study.

Toxic cardiomyopathy caused by naturally occurring substances had been a rare disease in experimental animals. We had experienced another mycotoxin. xanthoascin ${ }^{10}$ produced by Aspergillus candidus, causing myocardial changes along with liver injury"1.12. Xanthoascin induces myocardial necrosis by single oral or parenteral administration and also by moldy rice feeding". Cardiac lesion developed after a week, with diffuse vacuolation which corresponded myelin-like figures's in electron microscope (Fig. 13). Thus, the peak of the cardiac lesion was seen at the second or third week after administration of the toxin, while the liver necrosis preceded for about a week. and recovered by 3 weeks ${ }^{12}$. Except for the thymus, hematopoietic organs were only mildly damaged by xanthoascin"1 in contrast to chaeto- chromin.

The cardiac lesions induced by chaetochromin and xanthoascin were similar in the early phase in that the mitochondrial alteration seemed to be the initial event, followed by appearance of the myelin-like structures. But later, the lesions were different ; by chaetochromin, focal necrosis resulting in calcification and foreign body reaction occurred, while by xanthoascin, diffusely distributed myelin-like figures accumulated perinuclearly without noticeable necrosis. The foreign body granulomas were reminiscent of those observed in an experimental viral myocarditis ${ }^{14}$.

Recently other mycotoxins have been reported to cause cardiac lesions. Cardiac toxicity of some trichothecenes has been well established. T-2 toxin, in particular, causes myocardial degeneration and necrosis in swine and rats, with impairment of cardiac function 1s-18.

Antitumor agents, adriamycin and its derivatives, are the most important therapeutics that cause cardiac lesions involving myocytes and the interstitium. Side effects of these drugs on human hearts have been well reviewed ${ }^{10.20}$. Experimental myocardial damages have also been reported since the 70's, using rabbits ${ }^{21,22}$, hamsters ${ }^{22}$, and rats $^{23}$.

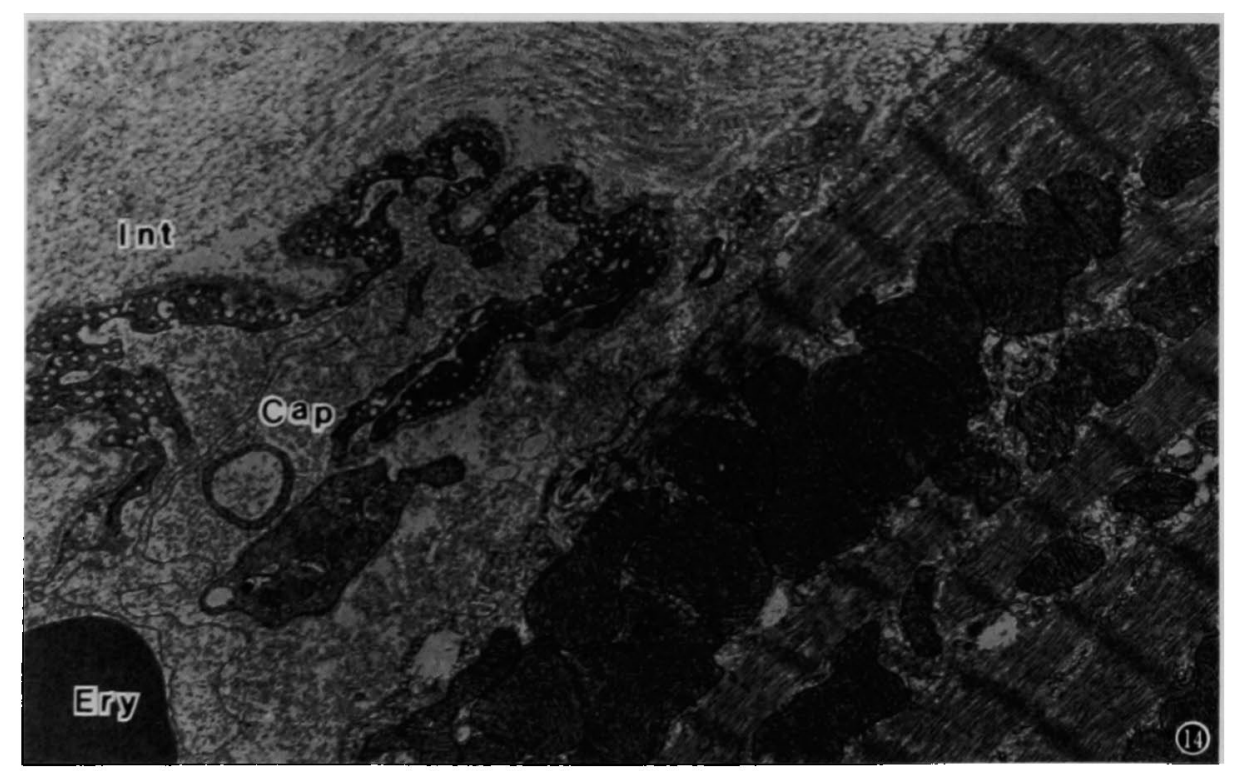

Fig. 14. Adriamycin (10 mg/kg b.w., ip. injection)-induced myocardial changes in a Wistar male rat, aged 5 weeks. After 3 weeks of administration, myofibrils are loosely separated and mitochondria are enlarged. A capillary (Cap) is ruptured and endothelial cells are condensed and vacuolated. The interstitium (Int) is edernatous with exudated serous material. Ery : erythrocyte. $\times 8,900$. 
The common ultrastructural changes following subchronic administration were single cell or focal myocyte degeneration with myofibril disorganization and separation, vacuolation and mitochondrial degradation, and interstitial edema and/or fibrosis ${ }^{19,21-24}$. Our preliminary single-injection experiment in rats revealed myofibril degeneration and separation with interstitial edema after 3 weeks (Fig. 14). Focal collagen loss revealed by SEM $^{25}$ was not apparent in our TEM observation. Although mitochondrial enlargement was noted. no membranous structures such as seen in the mycotoxin-induced ones described above were observed.

Acknowledgments : We wish to thank Prof. S. Natori of Meiji Pharmaceutical College and Dr. S. Sekita of National Institute of Hygenic Sciences. for their generous gin of chaetochromin. Mr. K. Nakamura and Mr. N. Izumiyama for their skillful technical assistance, and Mr. Y. Fujita for his photographic assistance.

\section{References}

1. Koyama, $\mathbf{K}$ and Natori, S: Chaetochromins B, C and $D$, bis (naphtho- $\gamma$-pyrone) derivatives from Chaetomium gracile. Chem Pharm Bull 35 : 578584, 1987.

2. Koyama, K, Natori, S, and litaka, Y: Absolute configurations of chactochromin $A$ and related bis (naphtho-y-pyrone) mold metabolites. Chem Pharm Bull 35: 4049-4055, 1987.

3. Natori, S: Toxic cytochalasins. In : Mycotoxins in Human and Animal Health, JV Rodricks. CW Hesseltine and MA Mehlman Eds, Pathotox Pub. Park Forest South, IL. pp. 559-581, 1977.

4. Sekita, S, Yoshihira, K, Natori, S, Udagawa, S. Muroi, T, Sugiyama, Y, Kurata, $H$, and Umeda, $M$ : Mycotoxin production by Chaetomium spp. and related fungi. Can J Microbiol, 27 : 766-772, 1981.

5. Udagawa, S, Muroi, T, Kurata, H, Sekita, S, Yoshihira. K, Natori, S, and Umeda, $M$ : The production of chretoglobosins, sterigmatocystin, $O$-methylsterigmatocystin, and chaetocin by Chaetomium spp. and related fungi. Can J Microbiol 25 : 170-177. 1979.

6. Sekita. S. Yoshihira. K, and Natori, S : Chaetochromin, a bis (naphthodihydropyran-4-one) mycotoxin from Chaetomium thielavioideum: application of ${ }^{19} \mathrm{C}-{ }^{\prime} \mathrm{H}$ long-range coupling to the structure elucidation. Chem Pharm Bull 28 : 2428-2435. 1980.

7. Ohtsubo, K: Oral toxicity of chaetochromin, a new mycotoxin produced by Chaetomium virescens, to mice. Proc Jpn Assoc Mycotoxicol 12: 28-29, 1980.

8. Ohtsubo, K: Hematopoietic injury and liver ne- crosis in the mice fed chaetochromin-containing moldy rice diet. Proc Jpn Assoc Mycotoxicol 15 : 25-27, 1982.

9. Ito, $Y$ and Ohtsubo, $K$ : Teratogenicity of oral chaetochromin, a polyphenolic mycotoxin produced by Chaetomium spp., to mice embryo. Bull Environ Contam Toxicol 39 : 299-303. 1987.

10. Takahashi, C, Sekita, S, Yoshihira, K, and Natori, $\mathrm{S}$ : The structures of toxic metabolites of Aspergillus candidus: II. The compound B (xanthoascin), a hepato- and cardiotoxic xanthocillin analog. Chem Pharm Bull 24: 2317-2321, 1976.

11. Ohtsubo, K, Enomoto, M. Ishiko, T, Saito, M, Sakabe, F, Udagawa, S, and Kurata, $H$ : Toxicity to mice and rats of molded rice of some mycotoxin producing fungi isolated from foodstuffs. Jpn J Exp Med 44: 477-483. 1974.

12. Ohtsubo, K, Horiuchi, T, Hatanaka, Y, and Saito, $M$ : Hepato- and cardiotoxicity of xanthoascin, a new metabolite of $A$. candidus Link, to mice: $I$. Blood chemistry and histological changes in mice. Jpn J Exp Med 46 : 277-287, 1976.

13. Ohtsubo $K$, and Saito, $M$ : Hepato- and cardiotoxicity of xanthoascin, a new metabolite of A. candidus Link, to mice: II. A preliminary electron microscopic observation of the heart and lung with intranuclear myelin-like figures. Ann Nutr Alim 31: $771-780,1977$.

14. Ohtsubo. K: Coxsackie virus. In: Fluorescent Antibody Techniques and their Applications, 2nd ed., A Kawamura Ed. Univ. Tokyo Press \& Univ. Park Press, Tokyo and Baltimore, pp. 203-205, 1977.

15. Yarom, R, More, R, Sherman, Y, and Yagen, B : $T-2$ toxin-induced pathology in the hearts of rats. Br J Exp Pathol 64: 570-577, 1983.

16. Pang. VF, Adams, JH, Beasley, VR, Buck, WB, and Haschek, WM: Myocardial and pancreatic lesions induced by $T 2$ toxin, a trichothecene mycotoxin, in swine. Vet Pathol 23 : 310-319, 1986.

17. Magnuson, BA. Schiefer, HB, Hancock, DS, and Bhatti, AR: Cardiovascular effects of mycotoxin T-2 after topical application in rats. Can J Physiol Pharmacol 65: 799-802, 1987.

18. Lorenzana, RM. Beasley, VR, Buck, WB, Ghent, AW. Lundeen, GR, and Poppenga. RH : Experimental T-2 toxicosis in swine: I. Changes in cardiac output, aortic mean pressure, catecholamines, 6 keto-PGF 1 , thromoxane $B_{2}$, and acid-base parameters. Fundam Appl Toxicol 5 : 879-892, 1985.

19. Billingham, ME : Some recent advances in cardiac pathology. Human Pathol 10 : 367-386, 1979.

20. Kantrowitz, NE and Bristow, $M$ : Cardiotoxicity of antitumor agents. Prog Cardiovasc Dis 27 : 195200, 1984.

21. Jaenke, RS: An anthracycline antibiotic-induced cardiomyopathy in rabbits. Lab Invest $30: 292$ 304, 1974.

22. Wakabayashi, T, Oki, T, Tone, H, Hirano, S, and Omori, K: A comparative electron microscopic study of aclacinomycin and adriamycin cardiotoxicities in rabbits and hamsters. J Electron Microsc 
29 : 106-118, 1980.

23. Olson, HM and Capen, CC: Subacute cardiotoxicity of adriamycin in the rat: biochemical and ultrastructural investigations. Lab Invest 37 : 386394. 1977.

24. Buja, LM, Ferrans, VJ, Mayer, RJ, Roberts, WC. and
Henderson, ES: Cardiac ultrastructural changes induced by daunorubicin therapy. Cancer 32 : $771-788,1973$.

25. Caufield, JB and Bittner, V : Cardiac matrix alterations induced by adriamycin. Am J Pathol 133: 298-305, 1988. 